\title{
Acidose metabólica na doença renal crônica: abordagem nutricional
}

\author{
Metabolic acidosis in chronic kidney \\ disease: the nutritional approach
}

Viviane de Oliveira LEAL ${ }^{1}$

Maurilo LEITE JÚNIOR²

Denise MAFRA ${ }^{1}$

A acidose metabólica é uma das complicações da doença renal crônica e está associada ao aumento do catabolismo protéico, à diminuição da síntese de proteínas e ao balanço nitrogenado negativo. A dieta tem forte influência sobre a geração de ácidos, podendo contribuir, portanto, para determinar a gravidade da acidose no paciente com doença renal crônica. Alguns pesquisadores têm observado que é possível estimar a excreção ácida renal, e que o cálculo dessa carga ácida a partir de alguns componentes da dieta, permitiria uma predição apropriada dos efeitos da dieta na acidose metabólica. Este artigo é uma comunicação sobre as bases fisiológicas, bem como as implicações clínicas da acidose em pacientes com doença renal crônica e a influência da dieta no balanço ácido-básico desses pacientes.

Termos de indexação: Acidose. Desnutrição energético-protéica. Dieta. Doença renal crônica.

\section{A B S T R A C T}

Metabolic acidosis is a common manifestation of chronic kidney disease and is associated with increased protein catabolism, decreased protein synthesis and negative nitrogen balance. Diet strongly influences acid generation, determining the level of acidosis in chronic kidney disease patients. Some researchers have observed that it is possible to estimate renal net acid excretion, and the analysis of the renal acid load of selected, frequently consumed foods may allow an appropriate prediction of the effects of diet on metabolic acidosis. This article discusses the physiological bases as well as the clinical implications of acidosis in patients with chronic kidney disease and the influence of the diet on the acid-base balance of these patients.

Indexing terms: Acidosis. Protein-energy malnutrition. Diet. Chronic kidney disease.

${ }^{1}$ Universidade Federal Fluminense, Faculdade de Nutrição, Departamento de Nutrição e Dietética. R. São Paulo, 40, 4ํandar, Sala 406, Campus do Valonguinho, 24015-110, Centro, Niterói, RJ, Brasil. Correspondência para/Correspondence to: V.O. LEAL. E-mail: <vivianenutricao@yahoo.com.br>.

2 Universidade Federal do Rio de Janeiro, Faculdade de Medicina, Departamento de Clínica M édica. Rio de Janeiro, RJ, Brasil. 


\section{N T R O D U Ç Ã O}

Os rins mantêm a composição do meio interno por meio de funções que atuam no equilíbrio hidrossalino, eletrolítico e ácido-básico ${ }^{1}$. Uma das manifestações da disfunção crônica deste órgão é a acidose metabólica, pela queda da filtração glomerular e conseqüente diminuição da excreção de hidrogênio ${ }^{2}$. Este íon é altamente reativo, particularmente com porções de moléculas protéicas de carga negativa. Qualquer variação na sua concentração produz impacto significativo sobre as funções celulares, pois quase todos os sistemas enzimáticos do organismo e as proteínas envolvidas na coagulação e contração muscular são influenciados pela concentração de íons hidrogênio ${ }^{3}$.

0 desequilíbrio nos mecanismos de regulação do balanço ácido-básico, que comumente ocorre nos pacientes com doença renal crônica (DRC), tem na dieta uma importante variável para o desenvolvimento da acidose nesses pacientes. $\mathrm{Na}$ vigência de uma elevada ingestão de alimentos protéicos ricos em aminoácidos sulfurados, cujo catabolismo gera componentes ácidos, há maior produção de carga ácida que, em conseqüência da falência renal, não será devidamente eliminada ${ }^{4-10}$. Por sua vez, a acidose pode constituir mais um fator capaz de produzir repercussões no estado protéico-energético do paciente, conduzindo a um maior catabolismo protéico e ao balanço nitrogenado negativo ${ }^{11}$. Este comprometimento do estado nutricional tem sido fortemente correlacionado ao aumento da morbimortalidade nos pacientes portadores de DRC ${ }^{12}$. Esta comunicação abordará aspectos relacionados à fisiopatologia da acidose na DRC, suas implicações clínicas e a influência da dieta sobre o aumento da carga ácida nestes pacientes.

\section{Equilíbrio ácido-básico}

Para que seja mantida a estabilidade do meio interno deve haver equilíbrio entre a produção e a remoção de íons hidrogênio $\left(\mathrm{H}^{+}\right)$no organismo. Além dos rins, fundamentais na eliminação do $\mathrm{H}^{+}$, outros órgãos estão relacionados ao balanço ácido-básico, como o intestino, o fígado e os pulmões, 13,14 (Figura 1).

O intestino está diretamente envolvido no equilíbrio ácido-básico, devido ao seu papel na absorção de ácidos e bases derivados dos alimentos e por conduzir ânions orgânicos e aminoácidos sulfurados para serem oxidados no fígado ${ }^{13,14}$. Também é capaz de absorver uma quantidade variável de ácidos orgânicos produzidos pela microflora intestinal, como os ácidos acético, butírico e

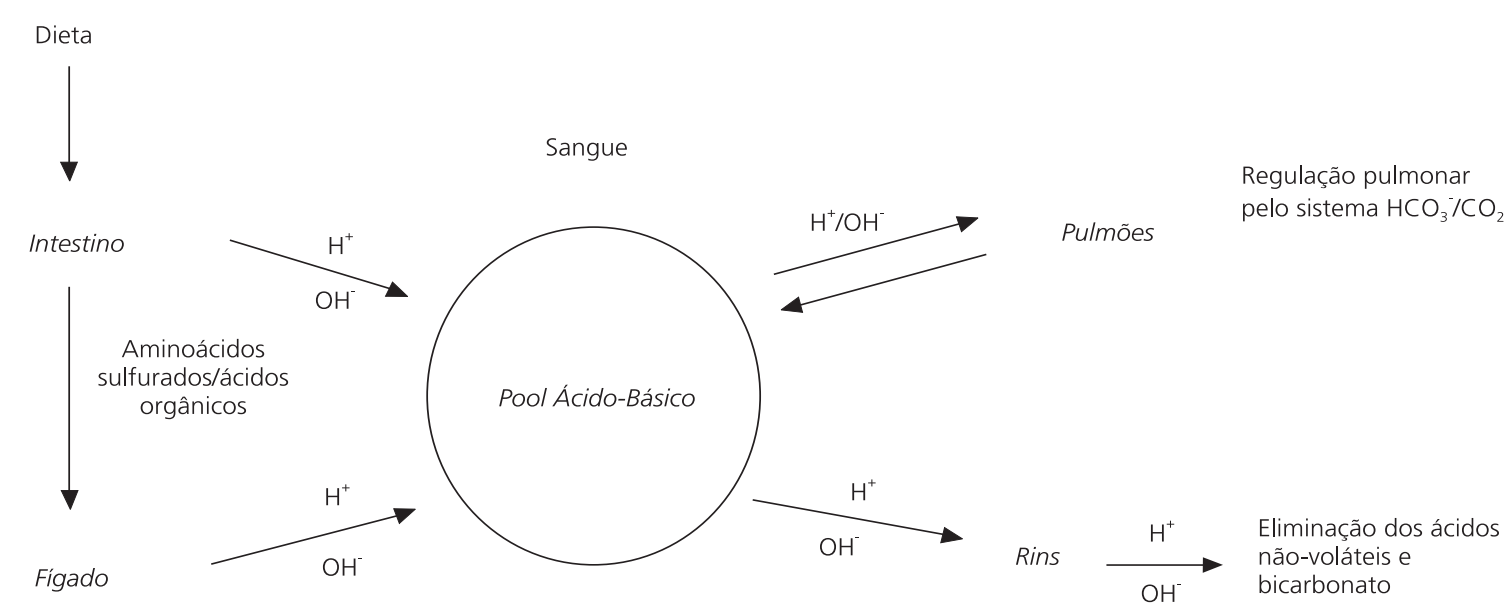

Figura 1. Inter-relação dos órgãos no equilíbrio ácido-básico.

Adaptado de Remer ${ }^{13}$ 
propiônico. Estes ácidos exercem pouco efeito no balanço ácido-básico, por serem completamente metabolizados ou removidos pelos rins. Estudos recentes revelaram a presença de carreadores na membrana das células do intestino distal, capazes de trocar ânions inorgânicos, como o sulfato, ou ácidos orgânicos não-metabolizáveis, como 0 oxalato, por ânions metabolizáveis ou, diretamente por bicarbonato. Conseqüentemente, ocorreria mínima alteração no equilíbrio ácido-básico ou ganho de bases ${ }^{8}$.

O fígado, por sua vez, produz grandes quantidades de íons hidrogênio eálcalis derivados da oxidação dos aminoácidos sulfurados e de ânions orgânicos, respectivamente. Inicialmente, estes íons hidrogênio são neutralizados por tampões existentes nos fluidos intracelulares e depois de serem liberados pelas células na circulação, se juntam ao pool ácido-básico do sangue, e, então, seguem por dois destinos: os pulmões e os rins. Os pulmões são capazes de promover a compensação respiratória do pH sanguíneo pelo sistema tampão bicarbonato/gás carbônico. Porém, mesmo que possa alterar o pH, esse processo não é capaz de induzir a perda de íons hidrogênio, pois os pulmões são incapazes de regenerar o bicarbonato perdido ${ }^{13,14}$.

Já os rins, são capazes de eliminar osácidos orgânicos metabolizáveis, derivados de proteínas, carboidratos e lipídios da dieta ou endógenos, produzidos pelo metabolismo orgânico normal, como ácidos lático e tricarboxílico. Os rins removem, ainda, os ácidos orgânicos não-metabolizáveis, como o glicurônico e o hipúrico, assim como os ácidos inorgânicos. Porém, somente quantidades irrelevantes de ácidos fortes, como o sulfúrico, podem ser eliminadas, uma vez que os rins não podem elaborar urina mais ácida do que um $\mathrm{pH}$ de 4,4. Conseqüentemente, aceptores adequados de $\mathrm{H}^{+}$devem neutralizar os íons hidrogênio secretados $s^{8,13,14}$.

Um importante tampão é a amônia, que se combina com os íons hidrogênio nos túbulos renais, de forma a ser excretada como sais de amônio. A amônia é sintetizada pelas células do túbulo proximal pela desaminação da glutamina na presença de glutaminase e se difunde através da membrana lipídica das células do fluido tubular até reagir com $\mathrm{H}^{+}$, formando o íon amônio $\left(\mathrm{NH}_{4}{ }^{+}\right)$. Esta via de eliminação dos íons hidrogênio gera um novo íon bicarbonato para cada $\mathrm{H}^{+}$que é excretado, o qual volta à circulação sanguínea para restabelecer a homeostasia do bicarbonato $2,13,14$.

Outra via de eliminação dos íons $\mathrm{H}^{+}$capaz de regenerar bicarbonato é o tampão não-bicarbonato do lúmen tubular. Seu principal representante éo tampão fosfato, presente no filtrado glomerular, e que funciona como aceptor de íons hidrogênio ${ }^{2}$.

Os rins desempenham outro papel importante no equilíbrio ácido-básico: a reabsorção do bicarbonato. Isso é possível através do transporte acoplado ao sódio em membrana basolateral e do contra-transporte $\mathrm{H}^{+} / \mathrm{Na}^{+}$em membrana luminal ${ }^{13,14}$. Na luz tubular, 0 ácido secretado se combina com o bicarbonato filtrado, formando ácido carbônico $\left(\mathrm{H}_{2} \mathrm{CO}_{3}\right)$, que é convertido em $\mathrm{CO}_{2} \mathrm{e}$ água. $\mathrm{O} \mathrm{CO}_{2}$ se difunde para dentro da célula, na qual se combina com a hidroxila $\left(\mathrm{OH}^{-}\right)$resultado da dissociação da água, e, novamente, sob a ação da anidrase carbônica, forma bicarbonato. Este, finalmente, se difunde passivamente para o fluido peritubular e o sangue ${ }^{3}$.

\section{Acidose metabólica da uremia}

Na DRC o bicarbonato plasmático neutraliza os ácidos produzidos, mas não é regenerado total ou parcialmente devido à função renal reduzida. Isso se deve à diminuição na excreção de íons hidrogênio, e, conseqüentemente, menor regeneração de bicarbonato, ocasionando redução de seus níveis plasmáticos ${ }^{10}$.

A extensão da falência renal e, conseqüentemente, de suas comorbidades é avaliada pela estimativa da taxa de filtração glomerular (TFG) e, segundo esta, a DRC é dividida em 5 estágios. Os estágios de 1 a 4 (usualmente com TFG de 60 a $15 \mathrm{~mL} / \mathrm{min}$ ) correspondem ao trata- 
mento conservador e no estágio 5 (TFG $<15 \mathrm{~mL} / \mathrm{min}$ ), geralmente, o paciente é direcionado à terapia renal substitutiva, sendo a hemodiálise a mais comum ${ }^{15}$.

Independentemente do estágio da DRC, a acidose é, geralmente, moderada (bicarbonato de 12 a $18 \mathrm{mEq} / \mathrm{L})$, não sendo comum a presença de grave acidemia $(\mathrm{pH}<7,2)^{4,8}$. A maioria dos casos de acidose urêmica é caracterizada por ânion gap (AG) aumentado, geralmente não excedendo 25 a $30 \mathrm{mEq} / \mathrm{L}$, caracterizando acidose normoclorêmica ${ }^{1,4,8,10}$.

A manutenção de níveis de bicarbonato maiores que $22 \mathrm{mEq} / \mathrm{L}$ deve ser uma meta para pacientes com DRC ${ }^{16}$. Há evidências de que a diálise peritoneal possibilita um melhor controle ácido-básico do que a hemodiálise ${ }^{8}$. Alguns pesquisadores demonstraram que a maioria dos pacientes em diálise peritoneal possui uma adequada concentração de bicarbonato sérico e que valores elevados de AG são comuns neste tipo de terapia renal substitutiva ${ }^{17,18}$. Nos pacientes em programa de hemodiálise, a acidose metabólica ocorre intermitentemente, pois durante o intervalo interdialítico os níveis de bicarbonato sérico decrescem continuamente ${ }^{9}$.

Na DRC, a acidose metabólica, geralmente, não é observada até que a TFG atinja valores inferiores a $20 \mathrm{~mL} / \mathrm{min}^{4,10}$. Porém, a gravidade da acidose pode variar mesmo em pacientes com graus semelhantes de falência renal. Isso ocorre em função da doença de base quando a lesão preferencialmente tubular altera diretamente 0 sítio de acidificação luminal, e também por particularidades em sua dieta ou ainda pela geração do bicarbonato extra-renal19.

As fontes potenciais de bicarbonato extra-renal poderiam ser, de um modo geral, o metabolismo de ânions cetoácidos ou ânions orgânicos gerados pela microflora intestinal ${ }^{19}$. M essa et al. ${ }^{8}$ citam outros fatores extra-renais que podem influir no grau de acidose desenvolvida por pacientes urêmicos, como 0 aumento na absorção de álcalis pelo intestino, a possibilidade de troca aniônica no sítio intestinal induzida pela uremia, além das mudanças na composição dietética.

\section{Implicações clínicas da acidose metabólica}

A acidose metabólica tem sido identificada como um fator contribuinte para o catabolismo protéico. Estudos têm mostrado que a acidose é o estímulo inicial para a ativação e a transcrição de genes que codificam enzimas que participam da via proteolítica ubiquitina-proteassoma dependente de adenosina trifosfato (ATP), levando à proteólise muscular ${ }^{1,10,17,18,20-24}$. Esta via proteolítica utiliza energia para reações que conjugam a ubiquitina aos substratos protéicos que são destinados à degradação. Essa conjugação culmina no reconhecimento da proteína pelo proteassoma, que, por sua vez, remove a ubiquitina da proteína a ser degradada e, em seguida, o substrato protéico é inserido no centro do proteassoma e rapidamente degradado a peptídeos, o que também requer energia ${ }^{23}$. Peptidases citoplasmáticas degradam esses peptídeos a aminoácidos. Contudo, esta via proteolítica não é capaz de, sozinha, degradar a complexa estrutura protéica muscular. Por esse motivo, a protease caspase- 3 cliva a actomiosina e as miofibrilas em actina, miosina e seus fragmentos, e estes, por sua vez, senvirão como substrato para a via ubiquitina-proteassoma. Tanto a caspase-3 quanto a própria via proteolítica ubiquitina-proteassoma parecem ser ativadas por um mesmo sinal: baixa atividade da via de ativação do fosfatidilinositol ${ }^{24}$.

Vale ressaltar que a insulina age como hormônio supressor da via ubiquitina-proteassoma. Assim, a resistência à insulina na uremia poderia também contribuir com o aumento da degradação protéica na $\mathrm{DRC}^{11,21,24,25}$. Há ainda evidências de que o cortisol seja necessário para a ativação da via ubiquitina-proteassoma ${ }^{20,24}$. Na DRC, a acidose seria o estímulo inicial para a ativação desta via, seguida por maior secreção de glicocorticóides. Esses seriam responsabilizados pelo aumento de RNAm das proteínas da via proteolítica ${ }^{12}$. Parece existir uma correlação positiva entre níveis de cortisol e degradação muscular e uma correlação negativa entre cortisol e bicarbonato sérico, sugerindo uma participação do cortisol na proteólise 
estimulada pela acidose metabólica. Entretanto, alguns achados não reforçam a afirmação de estarem elevados os níveis de cortisol na DRC ${ }^{25}$. Alguns autores sugerem que os glicocorticóides são necessários, mas não suficientes para estimular a proteólise pela via ubiquitina-proteassoma ${ }^{24}$. Além disso, recentemente foi descoberto um elemento responsivo a glicocorticóides na região promotora da desidrogenase cetoácida de cadeia ramificada (DCCR), sugerindo que esses hormônios possam estar envolvidos na ativação dessa desidrogenase $^{17}$. 0 catabolismo protéico na acidose é também estimulado pelo aumento na oxidação de aminoácidos de cadeia ramificada (AACR), como valina, leucina e isoleucina. Essa resposta catabólica é resultado do aumento da atividade da DCCR, bem como do RNAm responsável pela codificação desta enzima ${ }^{1,11,17,18,20,21,24}$.

A acidose parece também exercer ação antianabólica, porém, em menor extensão que o estímulo ao catabolismo protéico. Em cultura de células musculares esqueléticas, observou-se uma redução na síntese protéica em meio ácido ${ }^{12}$. Os efeitos antianabólicos podem ser resultantes de alterações nos sistemas hormonais, como a redução na liberação do hormônio do crescimento ou resistência periférica a este. Pode ocorrer também redução significativa nos níveis plasmáticos do fator de crescimento insulínico (IGF-1) e no conteúdo hepático de RNAm para IGF-1. Hormônios tireoidianos exercem efeitos anabólicos, e a diminuição da função da tireóide induzida pela acidose pode contribuir para a redução da síntese protéica muscular ${ }^{17}$. Inúmeras outras repercussões da acidose metabólica têm sido documentadas e encontram-se no Quadro 1,4,7,8,10,12,17,18,21,24-28.

Como já visto, a ativação da via proteolítica ubiquitina-proteassoma é um dos principais eventos capazes de contribuir para o desgaste de massa magra, o qual pode participar do aumento da prevalência de desnutrição nos pacientes com DRC acidóticos ${ }^{20,21,23,24}$. Além da ativação da via

Quadro 1. Conseqüências clínicas e metabólicas da acidose metabólica em pacientes com DRC.

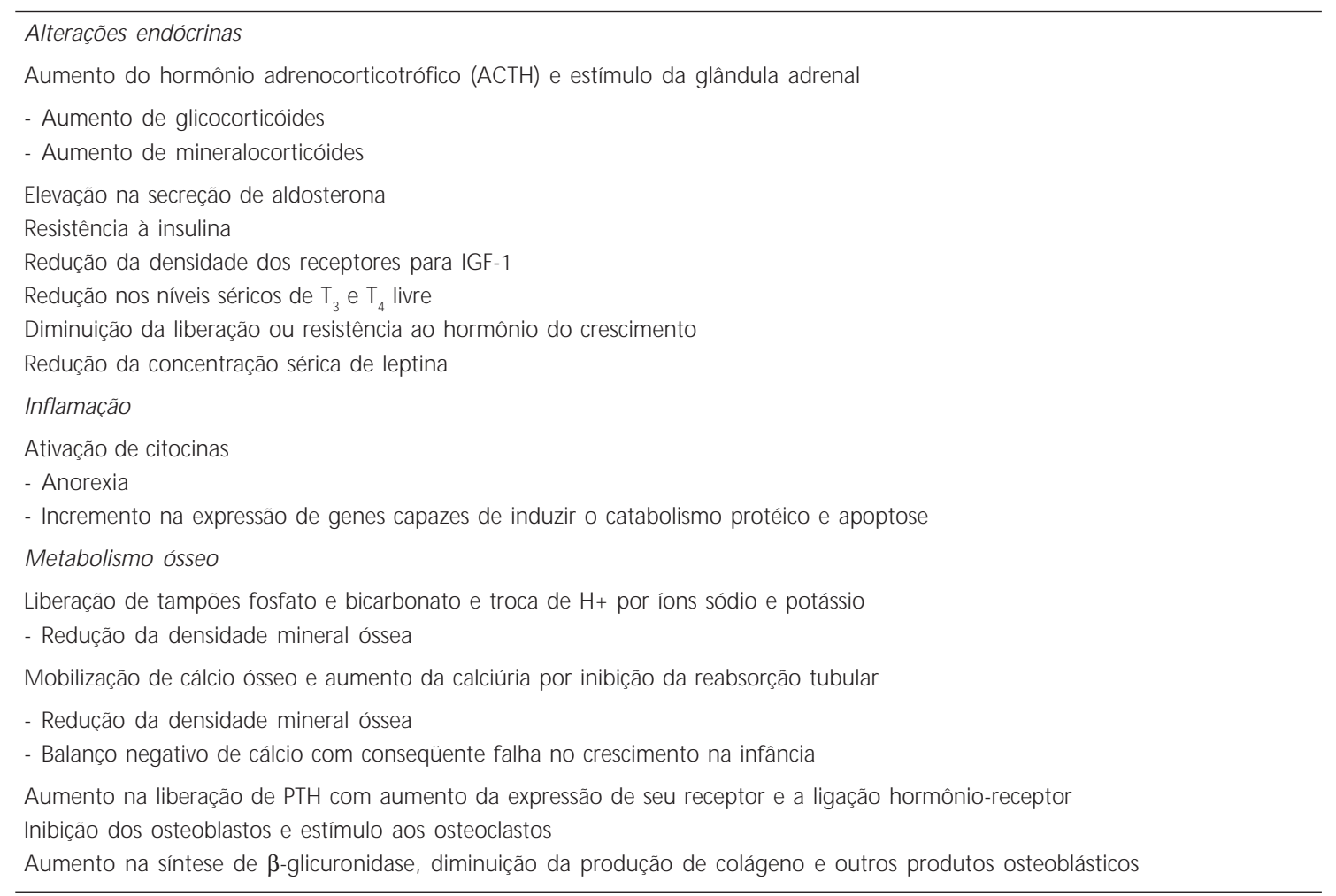

Adaptado de Kalantar-Zadeh et al. ${ }^{12}$. 
ubiquitina-proteassoma, outros caminhos podem conduzir à redução de massa magra na acidose metabólica (Figura 2).

Estudos mostraram que a correção da acidose parece suprimir o catabolismo muscular em indivíduos com função renal normal ou reduzida ${ }^{21}$. Essa correção pode ser feita pelo uso oral de bicarbonato de sódio ${ }^{29}$. Além disso, a acidose pode ser prevenida ou tratada por meio de orientações dietéticas adequadas como, por exemplo, a restrição protéica no tratamento pré-dialítico ${ }^{6,13,14}$. Dietas contendo níveis elevados de aminoácidos sulfurados irão interferir grandemente no nível de acidose metabólica, devido à produção ácida derivada da oxidação desses aminoácidos $4,6,10,17$.

\section{Dieta e acidose metabólica}

A hidrólise de proteínas e ácidos nucléicos forma ácido fosfórico e, principalmente, a oxidação hepática de aminoácidos que contêm enxofre (metionina e cistina), gera ácido sulfúrico $\left(\mathrm{H}_{2} \mathrm{SO}_{4}\right)^{12,21}$. Depois da entrada deste ácido no sangue, ele é tamponado pelo bicarbonato, gerando sal neutro $\left(\mathrm{NaSO}_{4}\right)$, gás carbônico e água. $\mathrm{O} \mathrm{CO}_{2}$ é eliminado pelos pulmões e o sal neutro é transportado para os rins, no qual o sódio é reabsorvido e o transporte acoplado de $\mathrm{Na}^{+} / \mathrm{HCO}_{3}{ }^{-}$possibilita a reabsorção do bicarbonato. Já o sulfato se combina à amônia e aos íons $\mathrm{H}^{+}$secretados, formando sulfato de amônio $\left(\left(\mathrm{NH}_{4}{ }^{+}\right) \mathrm{SO}_{4}{ }^{2}\right)$, que é, então, excretado na urina ${ }^{13,14}$. 0 metabolismo dos aminoácidos sulfurados encontra-se na Figura 3.

Bommer et al. ${ }^{9}$, ao avaliarem pacientes em hemodiálise, encontraram uma forte associação entre ingestão protéica e presença de acidose. Pacientes com concentrações de bicarbonato de, aproximadamente, $15 \mathrm{mEq} / \mathrm{L}$, consumiam dietas com elevado teor protéico, o que resultou em incremento no metabolismo das proteínas e, conseqüentemente, maior carga ácida produzida. Isso foi confirmado pela relação inversa entre bicarbonato e o Equivalente Protéico do Aparecimento do Nitrogênio Total (PNA), uma medida indireta do catabolismo de proteínas e sua ingestão, encontrado nos indivíduos estudados.

Nos pacientes com DRC ainda não submetidos à terapia renal substitutiva, a ingestão de dietas hipoprotéicas pode prevenir ou reduzir a gravidade da acidose por meio da diminuição da

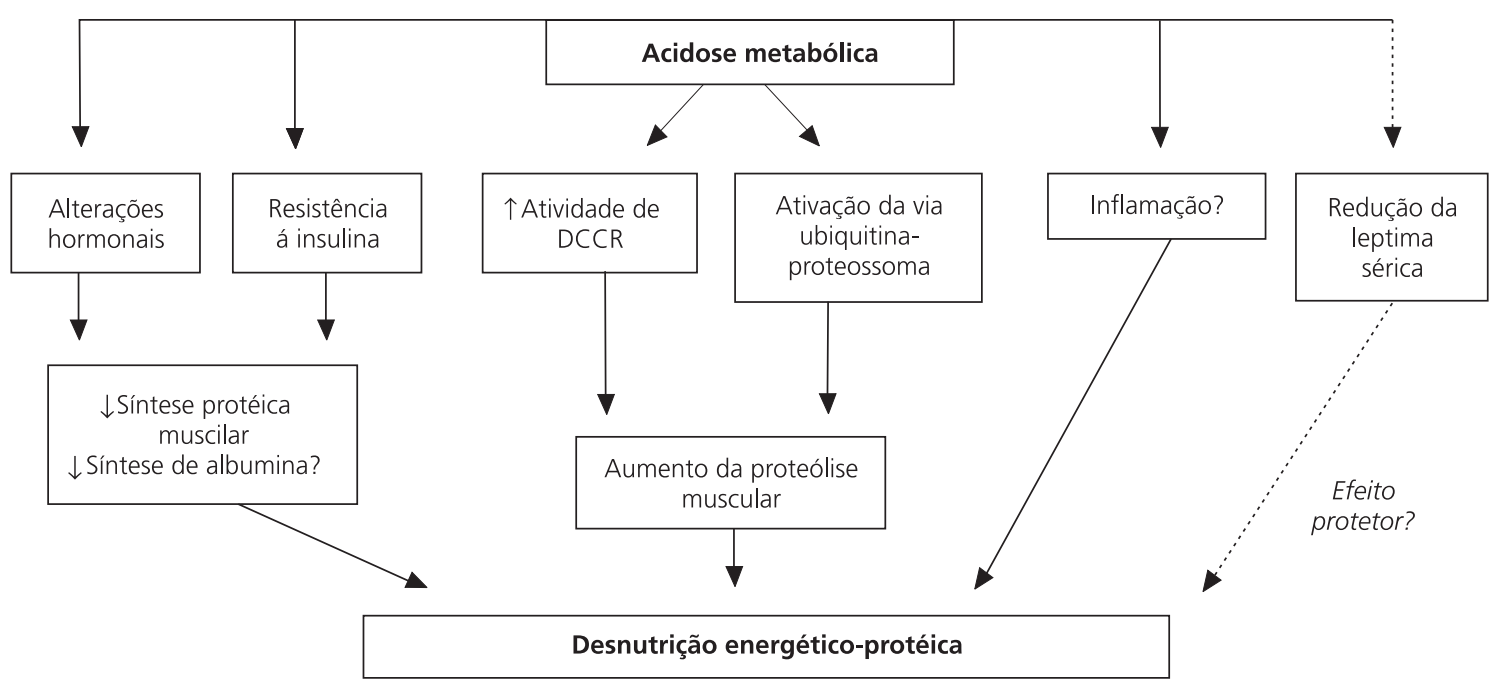

Figura 2. Mecanismos que podem conduzir à desnutrição energético-protéica na acidose metabólica.

A linha tracejada indica a regulação negativa da redução da leptina sérica no desenvolvimento da desnutrição. DCCR: Desidrogenase Cetoácida de Cadeia Ramificada. Adaptado de Mehrotra et al. ${ }^{17}$. 


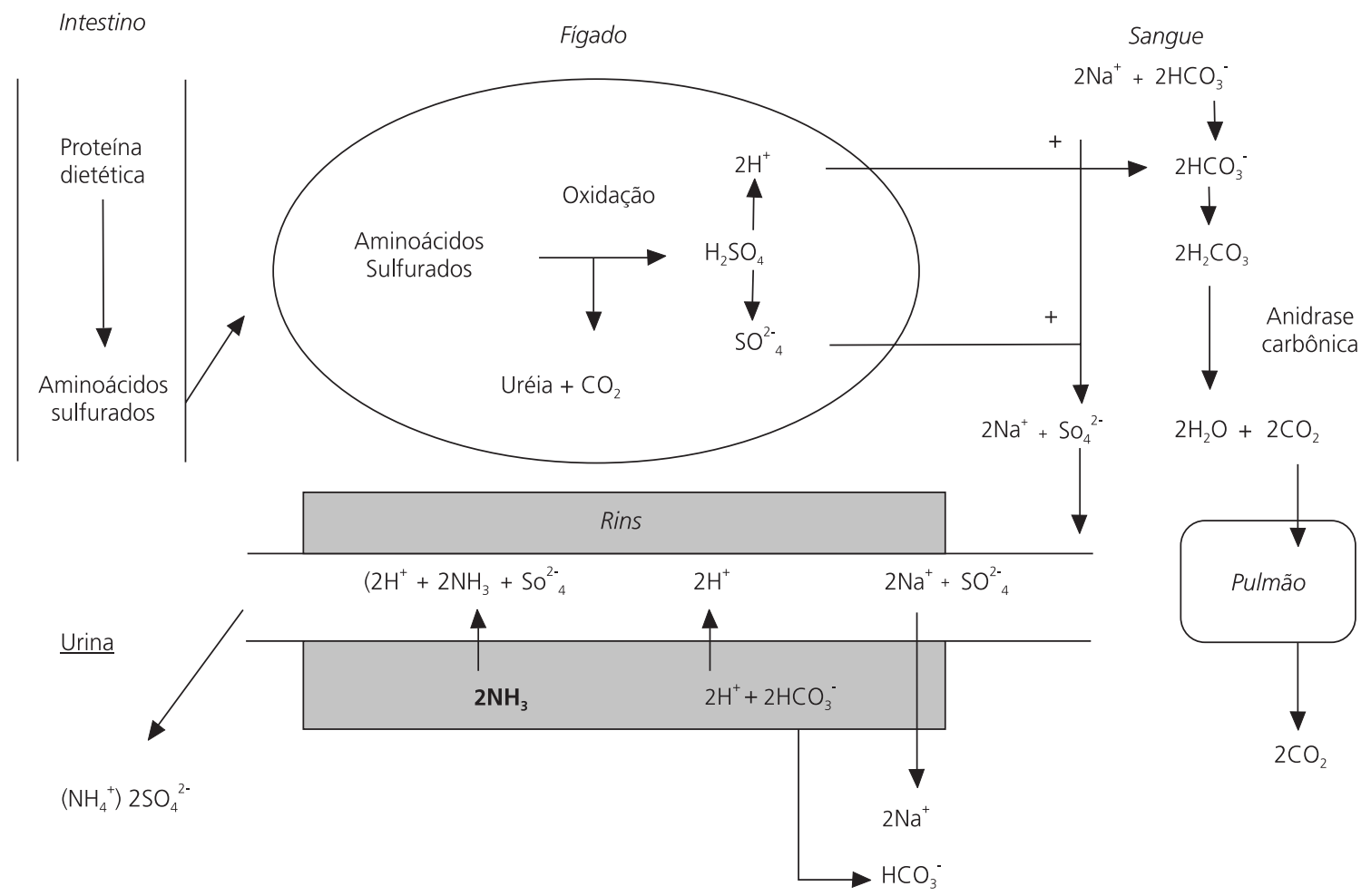

Figura 3. Metabolismo dos aminoácidos sulfurados.

Adaptado de Remer ${ }^{13}$.

geração endógena de produtos ácidos derivados do metabolismo das proteínas ${ }^{5,6,9,10,21,25}$. É importante ressaltar que, nessa fase da doença, a dieta hipoprotéica pode também ser benéfica em retardar a deterioração da função renal7 ${ }^{7,30,31}$. Como para os pacientes em diálise há um aumento da necessidade protéica, segundo Remer ${ }^{13,14}$, isso poderia contribuir para o incremento na carga ácida e, conseqüentemente, para o desenvolvimento da acidose metabólica.

Uribarri et al. ${ }^{5}$, avaliando a associação entre acidose e parâmetros nutricionais em pacientes em hemodiálise, concluíram que a acidose no início do tratamento é comum e pode ser resultado do incremento na ingestão protéica, poisfoi encontrada uma correlação inversa entre níveis de $\mathrm{CO}_{2}$ sérico e PNA. Porém, não foi encontrada correlação entre $\mathrm{CO}_{2}$ sérico, albumina, IMC e parâmetros antropométricos. Gao et al. ${ }^{32}$ analisaram pacientes em programa de hemodiálise divididos em dois grupos, o primeiro com níveis de $\mathrm{CO}_{2}$ pré-diálise $\leq 19 \mathrm{mEq} / \mathrm{L}$ e o segundo com níveis $>19 \mathrm{mEq} / \mathrm{L}$, e não encontraram diferenças entre nível sérico de albumina e PNA entre os grupos. Entretanto, valores de nitrogênio uréico plasmático (BUN), fósforo e ácido úrico foram significativamente maiores no primeiro que no segundo grupo. Por outro lado, ao avaliar pacientes em tratamento conservador, Cupisti et al. ${ }^{33}$ encontraram correlação entre grau de acidose e desnutrição, determinada a partir da Avaliação Subjetiva Global (ASG). Pacientes com desnutrição leve a moderada, de acordo com a ASG, possuíam menores níveis de bicarbonato que aqueles sem nenhuma alteração.

A ausência de correlação entre acidose e parâmetros nutricionais pode ser explicada pelas inúmeras maneiras de avaliar o estado nutricional, como pela albumina sérica, por medidas antropométricas ou ainda empregando métodos subjetivos, como a ASG. Além disso, muitos dos estudos que relacionam a acidose ao comprometimento do estado nutricional são desenvolvidos em modelos experimentais, nos quais a acidose é severa e os níveis de bicarbonato são bem menores no 
grupo experimental que no controle. Sugere-se, portanto, que o comprometimento do estado nutricional dependa da gravidade da acidose e, como esta é geralmente moderada ou leve na DRC, as reservas protéica e energética desses pacientes não sofreriam depleção significante ${ }^{34}$.

Como visto, a dieta pode influenciar no equilíbrio ácido-básico, por contribuir com o aumento da carga ácida ou ainda por disponibilizar equivalentes básicos. Por esse motivo, modelos experimentais têm sido utilizados para estimar os efeitos da dieta no balanço ácido-básico.

\section{Modelo para estimação da excreção ácida renal (EAR) e da carga ácida potencial dos alimentos (CAPA)}

Em indivíduos saudáveis, mais de $70 \%$ da variação de $\mathrm{pH}$ urinário pode ser explicada pelas variações da EAR, a qual é bastante influenciada pela dieta. Por esse motivo foi desenvolvido um modelo para estimação dos efeitos da dieta na EAR e também na CAPA ${ }^{13}$.

O modelo de cálculo da EAR, apresentado no Quadro 2, é baseado na correção dos índices de absorção intestinal de minerais e aminoácidos sulfurados e no índice de excreção de ácidos orgânicos (AO) proporcional à superfície corporal. Nesse cálculo são utilizados três componentes urinários: ácidos orgânicos, bicarbonato e íon amônio. Assim, a EAR pode ser determinada indiretamente pela diferença entre a soma dos ânions não-bicarbonato e a soma dos cátions minerais excretados na urina $\left(E A R=\left(\mathrm{Cl}+\mathrm{PO}_{4}+\mathrm{SO}_{4}+\mathrm{AO}\right)\right.$ - $(\mathrm{Na}+\mathrm{K}+\mathrm{Mg}+\mathrm{Ca}$ )). Para este cálculo, também são considerados índices de absorção intestinal para proteínas e minerais, valência iônica do cálcio e magnésio e grau de dissociação do fósforo em $\mathrm{pH} 7,4$. Os aminoácidos sulfurados foram estimados como sendo $2 \%$ do conteúdo total de proteína para cistina e de $2,4 \%$ para metionina. Para a excreção renal de ácidos orgânicos foi assumido como normal, o valor de $41 \mathrm{mEq} / \mathrm{dia} / 1,73 \mathrm{~m}^{2}$, segundo a técnica desenvolvida pelos autores ${ }^{13,14}$.
Quadro 2. Cálculo da EAR.

\begin{tabular}{lcccc}
\hline $\begin{array}{l}\text { Excreção de } \\
\text { eletrólitos } \\
\text { estimada }\end{array}$ & $\begin{array}{c}\text { Índice de } \\
\text { absorção }\end{array}$ & Ingestão $\mathbf{X}$ & $\begin{array}{c}\text { Valência } \\
\text { iônica/grau de } \\
\text { dissociação }\end{array}$ \\
\hline $\mathrm{Na}(\mathrm{mmol})=$ & 0,95 & $\ldots \mathrm{mmol}$ & \\
$\mathrm{K}(\mathrm{mmol})$ & $=$ & 0,80 & $\ldots \mathrm{mmol}$ & 2,0 \\
$\mathrm{Ca}(\mathrm{mEq})=$ & 0,25 & $\ldots \mathrm{mmol}$ & 2,0 \\
$\mathrm{Mg}(\mathrm{mEq})=$ & 0,32 & $\ldots \mathrm{mmol}$ & \\
$\mathrm{Cl}(\mathrm{mmol})=$ & 0,95 & $\ldots \mathrm{mmol}$ & 1,8 \\
$\mathrm{PO}_{4}(\mathrm{mEq})=$ & 0,63 & $\ldots \mathrm{mmol}$ & 2,0 \\
$\mathrm{SO}_{4}(\mathrm{mEq})=$ & 0,75 & $\ldots \mathrm{g} \mathrm{proteína} \mathbf{X ~ 0 , 3 2 5 *}$ & 2,0 \\
\hline
\end{tabular}

X Área da Superfície Corporal

$\mathrm{AO}(\mathrm{mEq}) \quad 41 \mathrm{mEq} \quad\left(\mathrm{m}^{2}\right) / 1,73\left(\mathrm{~m}^{2}\right)$

EAR: $\left(\mathrm{Cl}+\mathrm{PO}_{4}+\mathrm{SO}_{4}+\mathrm{AO}\right)-(\mathrm{Na}+\mathrm{K}+\mathrm{Mg}+\mathrm{Ca})$

* Conteúdo médio de metionina e cistina $(2,4 \%$ e $2 \%$ do total de proteína, respectivamente) expresso como $\mathrm{mmol} / \mathrm{g}$ proteina. Adaptado de Remer ${ }^{14}$.

Por meio da CAPA, a EAR pode ser estimada com segurança a partir da composição das dietas. Para esse cálculo também foram consideradas a biodisponibilidade de nutrientes e íons relevantes, bem como seu conteúdo nos alimentos, valência iônica, grau de dissociação e média do conteúdo de aminoácidos sulfurados. Os valores de CAPA encontrados oscilam entre a máxima de $34,2 \mathrm{mEq} / 100 \mathrm{~g}$ para queijo parmesão, passando por $0 \mathrm{mEq} / 100 \mathrm{~g}$ para óleos e gorduras e atingindo um mínimo de $-21 \mathrm{mEq} / 100 \mathrm{~g}$ para uvas. Foram encontrados valores médios de CAPA de $4,0 \mathrm{mEq} / 100 \mathrm{~g}$ para batata, $-3,1 \mathrm{mEq} / 100 \mathrm{~g}$ para frutas e suco de frutas (exceto frutas secas) e -2,8 $\mathrm{mEq} / 100 \mathrm{~g}$ para vegetais (exceto espinafre e aspargos). Valores médios positivos de CAPA foram encontrados para leite e derivados, exceto queijos $(1,0 \mathrm{mEq} / 100 \mathrm{~g})$, pães $(3,5 \mathrm{mEq} / 100 \mathrm{~g})$, macarrão $(6,7 \mathrm{mEq} / 100 \mathrm{~g})$, farinhas $(7,0 \mathrm{mEq} / 100 \mathrm{~g})$, peixes $(7,9 \mathrm{mEq} / 100 \mathrm{~g})$, carnes e produtos cárneos $(9,5 \mathrm{mEq} / 100 \mathrm{~g})$. Para queijos com até $15 \mathrm{~g}$ de proteína $/ 100 \mathrm{~g}$, foram encontrados valores médios de CAPA de $8 \mathrm{mEq} / 100 \mathrm{~g}$ e para aqueles com mais de $15 \mathrm{~g} / 100 \mathrm{~g}$, valores de $23,6 \mathrm{mEq} / 100 \mathrm{~g}^{13,14}$.

Frutas e vegetais têm valores de CAPA negativos, ou seja, possuem potencial alcalinizante, sendo capazes de reduzir a excreção ácida. Leite e iogurte produzem cerca de $1 \mathrm{mEq}$, enquanto carne, peixe, queijo, aves e alguns produtos derivados 
de grãos produzem, potencialmente, $7 \mathrm{mEq}$ ou mais por $100 \mathrm{~g}$ de porção. Assim, como as diferentes fontes protéicas produzem cargas ácidas distintas, pode-se preferir aquelas que disponibilizam menos equivalentes ácidos, no caso de pacientes acidóticos. $\mathrm{E}$, mesmo que a dieta consumida contenha grande potencial acidificante, pode-se contrabalançar esse efeito com a ingestão de alimentos com potencial alcalinizante, como frutas e vegetais ${ }^{13,14}$.

A simples substituição de alimentos ricos em proteína por aqueles ricos em álcalis pode alterar a ingestão diária de equivalentes ácidos. Considerando, por exemplo, duas dietas hipotéticas ( $\mathrm{A}$ e B) com o mesmo conteúdo energético, aproximadamente, $1800 \mathrm{Kcal}$, e a seguinte distribuição de alimentos: Dieta A - pão (200g), carne $(200 \mathrm{~g})$, queijo tipo cottage $(50 \mathrm{~g})$, macarrão $(150 \mathrm{~g})$, leite integral $(300 \mathrm{~mL})$ e margarina/óleo para cocção (50g); Dieta B - pão (200g), carne (200g), vegetais $(500 \mathrm{~g})$, batatas $(400 \mathrm{~g})$, suco de laranja $(300 \mathrm{~mL})$ e margarina/óleo $(60 \mathrm{~g})$, a substituição do queijo por vegetais, do macarrão por batatas e do leite por suco de frutas, acarretaria uma redução da CAPA de $43 \mathrm{mEq}$ na Dieta A para apenas $-13,3 \mathrm{mEq}$ na Dieta $B$, ressaltando o potencial alcalinizante das frutas e dos vegetais. Neste exemplo, a excreção de ácidos orgânicos poderia ser estimada para um indivíduo de $63 \mathrm{~kg}$ utilizando a fórmula simplificada, na qual se considera apenas o peso corporal $(\mathrm{AO}=\text { peso } \times 0,66)^{13}$.

Como na DRC ocorre uma diminuição na capacidade de excreção de íons hidrogênio, o conhecimento a respeito da CAPA permite a redução da carga ácida pela manipulação dietética, 0 que pode contribuir para a prevenção ou o tratamento da acidose metabólica ${ }^{13}$.

Para validar a predição da EAR a partir da ingestão alimentar, Remer $\& M$ anz ${ }^{35}$ avaliaram a excreção ácida renal analítica e estimada de 6 adultos que consumiam 4 tipos de dietas distintas quanto ao teor protéico, e perceberam que ambas eram comparáveis. Assim, pode-se considerar que a EAR estimada é aplicável para adultos mesmo quando dietas selecionadas livremente são consumidas.
Remer \& $M$ anz $z^{36}$ também confirmaram a validade do cálculo da EAR pela coleta de amostras de urina e a realização de recordatório alimentar com 165 crianças e 73 adolescentes. A partir desses dados, os pesquisadores determinaram a EAR analisada e a EAR estimada e concluíram que esta última é também aplicável para crianças e adolescentes. Os pesquisadores concluíram, também, que a CAPA estimada a partir de apenas 4 nutrientes (proteína, fósforo, potássio e magnésio) pode fornecer uma simples estimativa da acidez de alimentos e dietas. Além desse cálculo simplificado da CAPA, o índice de ingestão protéica/potássio pode também ser considerado útil e rápido preditor da EAR, embora não considere a biodisponibilidade dos nutrientes.

Como visto neste trabalho, a acidose é deletéria ao paciente com DRC podendo causar, entre várias complicações, a redução de massa magra. A manipulação dietética pela substituição adequada de alimentos ricos em proteínas com aminoácidos sulfurados para aqueles ricos em álcalis, alterando a ingestão diária de equivalentes ácidos e reduzindo a carga ácida diária, se impõe como uma terapia alternativa para minimizar as conseqüências da acidose metabólica nos pacientes com doença renal crônica.

\section{COLABORADORES}

V.O. LEAL participou da determinação do enfoque do artigo da pesquisa bibliográfica, da discussão, da redação e da elaboração final do artigo. M. LEITE JÚNIOR participou da correção, discussão e elaboração final do artigo. D. M AFRA participou da orientação, discussão e elaboração final do artigo.

\section{REFERÊ N C IAS}

1. Kovacic V, Roguljic L, Kovacic V. M etabolic acidosis of chronically hemodialyzed patients. Am J Nephrol. 2003; 23(3):158-64.

2. Wiseman $A C$, Linas $S$. Disorders of potassium and acid-base balance. Am J Kidney Dis. 2005; 45(5): 941-9. 
3. Riella M C, Pachaly MA. M etabolismo ácido-básico. In: Riella MC. Princípios de nefrologia e distúrbios hidroeletrolíticos. Rio de Janeiro: Guanabara Koogan; 2003.

4. Nuhad I. Use of erythropoietin, active vitamin D3 metabolites and alkali agents in predialysis patients. Semin Nephrol. 1997; 17(4):270-84.

5. Uribarri J, Levin NW, Delmez J, Depner TA, Ornt D, Owen W, et al. Association of acidosis and nutritional parameters in hemodialysis patients. Am J Kidney Dis. 1999; 34(3):493-9.

6. Chauveau P, Fouque D, Combe C, Laville M, Canaud $B, A z a r$, et al. Acidosis and status nutritional in hemodialyzed patients. French Study Group for Nutrition in Dialysis. Semin Dial. 2000; 13(4): 241-6.

7. Metges $C$, Barth CA. M etabolic consequences of a high dietary-protein intake in adulthood: assessment of the available evidence. J Nutr. 2000; 130(4):886-9.

8. Messa P, M ioni G, Di Maio G, Ferrando C, Lamperi $D$, Famularo $A$, et al. Derangement of acid-base balance in uremia and under hemodialysis. J Nephrol. 2001; 14(4):S12-S21.

9. Bommer J, Locatelli $F$, Satayathum $S$, Keen $M L$, Goodkin DA, Saito A, et al. Association of predialysis serum bicarbonate levels with risk of mortality and hospitalization in the dialysis outcomes and practice patterns study (DOPPS). Am J Kidney Dis. 2004; 44(4):661-71.

10. Kraut JA, Kurtz I. Metabolic acidosis of CKD: diagnosis, clinical characteristics and treatment. Am J Kidney Dis. 2005; 45(6):978-93.

11. Mafra D, Burini RC. Atualização em nefrologia clínica: efeitos da acidose e do seu controle sobre o catabolismo de proteínas e aminoácidos na insuficiência renal crônica. J Bras Nefrol. 2000; 22(1):192-200.

12. Kalantar-Zadeh K, Mehrotra R, Fouque D, Kopple JD. Metabolic acidosis and malnutritioninflammation complex syndrome in chronic renal failure. Semin Dial. 2004; 17(6):455-65.

13. Remer T. Influence of diet on acid-base balance. Semin Dial. 2000; 13(4):221-6.

14. Remer T. Influence of nutrition on acid-base balance. Eur J Nutr. 2001; 40(5):214-20.

15. National Kidney Foundation. K/DOQI. Clinical practice guidelines for chronic kidney disease: evaluation, classification and stratification. Outcome Quality Initiative. Part 4. Definition and classification of stages of chronic kidney disease. Am J Kidney Dis. 2002; 39(2):S46-S75.
16. Kirschbaum B. The effect of hemodialysis on electrolytes and acid-base parameters. Clin Chim Acta. 2003; 336(1-2):109-13.

17. Mehrotra R, Kopple JD, Wolfson M. Metabolic acidosis in maintenance dialysis patients: clinical considerations. Kidney Int. 2003; 64(88):S13-S25.

18. Szeto CC, Chow KM. Metabolic acidosis and malnutrition in dialysis patients. Semin Dial. 2004; 17(5):371-5.

19. Caravaca F, Arrobas M, Pizarro JL, Espárrago JF. Metabolic acidosis in advanced renal failure: differences between diabetic and nondiabetic patients. Am J Kidney Dis. 1999; 33(5):892-8.

20. Bailey JL. Metabolic acidosis and protein catabolism: mechanisms and clinical implications. Miner Electrolyte Metab. 1998; 24(1):13-9.

21. Franch HA, Mitch WE. Catabolism in uremia: the impact of metabolic acidosis. J Am Soc Nephrol. 1998; 9(suppl 12):S78-S81.

22. Boirie Y, Broyer M, Gagnadoux MF, Niaudet P, Bresson JL. Alterations of protein metabolism by metabolic acidosis in children with chronic renal failure. Kidney Int. 2000; 58(1):236-41.

23. Mitch WE. Insights into the abnormalities of chronic renal disease attributed to malnutrition. J Am Soc Nephrol. 2002; 13(Suppl 1):S22-S27.

24. Du Z, Hu D, Mitch WE. Molecular mechanisms activating muscle protein degradation in chronic kidney disease and other catabolic conditions. Eur J Clin Invest. 2005; 35(3):157-63.

25. Kopple JD, Kalantar-Zadeh K, M ehrotra R. Risks of chronic metabolic acidosis in patients with chronic kidney disease. Kidney Int. 2005; 67(suppl 95): S21-S27.

26. Kokot F, Chudek J, Adamczak M, Wiecek A. Interrelationship between plasma leptin concentration and severity of metabolic acidosis in haemodialysed patients with chronic renal failure. Exp Clin Endocrinol Diabetes. 2001; 109(7): 370-3.

27. Zheng F, Qiu X, Yin S, Li Y. Changes in serum leptin levels in chronic renal failure patients with metabolic acidosis. J Ren Nutr. 2001; 11(4): 207-11.

28. Raj DSC, Shah H, Shah VO, Ferrando A, Bankhurst $A$, Wolfe $R$, et al. Markers of inflammation, proteolysis, and apoptosis in ESRD. Am J Kidney Dis. 2003; 42(6):1212-20.

29. Leite Jr M , Leal E, Cardoso LR. Correction of acidosis by hemodialysis: proposal of a correlation with urea kinetics. Blood Purif. 2002; 20(6):551-6.

30. Prakash S, Pande DP, Sharma S, Sharma D, Bal CS, Kulkarni H. Randomized, double-blind, placebo- 
-controlled trial to evaluate efficacy of ketodiet in predialytic chronic renal failure. J Ren Nutr. 2004; 14(2):89-96.

31. Feiten SF, Draibe SA, Watanabe R, Duenhas MR, Baxmann AC, Nerbass FB, et al. Short-term effects of a very-low-protein diet supplemented with ketoacids in nondialyzed chronic kidney disease patients. Eur J Clin Nutr. 1005; 59(1):129-36.

32. Gao H, Lew SQ, Bosch JP. Moderate metabolic acidosis and its effects on serum parameters in hemodialysis patients. Nephron. 2000; 86(2): 135-8.

33. Cupisti A, D’Alessandro C, Morelli E, Rizza GM, Galetta F, Franzoni F, et al. Nutritional status and dietary manipulation in predialysis chronic renal failure patients. J Ren Nutr. 2004; 14(3):127-33.
34. Bossola M, Muscaritoli M, Costelli P, Nanni G, Tazza $L$, Panochia N, et al. M uscle ubiquitin m-RNA levels in patients with end-stage renal disease on maintenance hemodialysis. J Nephrol. 2002; 15(5): 552-7.

35. Remer T, Manz F. Estimation of the renal net acid excretion by adults consuming diets containing variable amounts of protein. Clin Nutr. 1994; 59(6):1356-61.

36. Remer T, Manz F. Dietary potential renal acid load and renal net acid excretion in healthy, free-living children and adolescents. Am J Clin Nutr. 2003; 77(5):1255-60.

Recebido em: 26/4/2006

Versão final reapresentada em: 20/7/2007

Aprovado em: 22/10/2007 
